\title{
Good performances but short lasting efficacy of Actellic 50 EC Indoor Residual Spraying (IRS) on malaria transmission in Benin, West Africa
}

\author{
Rock Aïkpon ${ }^{1,2^{*}}$, Michel Sèzonlin², Filémon Tokponon ${ }^{3}$, Mariam Okè $^{3}$, Olivier Oussou ${ }^{1}$, Frédéric Oké-Agbo ${ }^{1}$,
} Raymond Beach ${ }^{4}$ and Martin Akogbéto ${ }^{1,2}$

\begin{abstract}
Background: The National Malaria Control Program (NMCP) has been using pirimiphos methyl for the first time for indoor residual spraying (IRS) in Benin. The first round was a success with a significant decrease of entomological indicators of malaria transmission in the treated districts. We present the results of the entomological impact on malaria transmission. Entomologic parameters in the control area were compared with those in intervention sites.

Methods: Mosquito collections were carried out in three districts in the Atacora-Dongo region of which two were treated with pirimiphos methyl (Actellic 50EC) (Tanguiéta and Kouandé) and the untreated (Copargo) served as control. Anopheles gambiae s.l. populations were sampled monthly by human landing catch. In addition, window exit traps and pyrethrum spray catches were performed to assess exophagic behavior of Anopheles vectors. In the three districts, mosquito collections were organized to follow the impact of pirimiphos methyl IRS on malaria transmission and possible changes in the behavior of mosquitoes. The residual activity of pirimiphos methyl in the treated walls was also assessed using WHO bioassay test.
\end{abstract}

Results: A significant reduction (94.25\%) in human biting rate was recorded in treated districts where an inhabitant received less than 1 bite of An. gambiae per night. During this same time, the entomological inoculation rate (EIR) dramatically declined in the treated area ( $99.24 \%$ reduction). We also noted a significant reduction in longevity of the vectors and an increase in exophily induced by pirimiphos methyl on An. gambiae. However, no significant impact was found on the blood feeding rate. Otherwise, the low residual activity of Actellic $50 \mathrm{EC}$, which is three months, is a disadvantage.

Conclusion: Pirimiphos methyl was found to be effective for IRS in Benin. However, because of the low persistence of Actellic 50EC used in this study on the treated walls, the recourse to another more residual formulation of pirimiphos methyl is required.

Keywords: IRS, Pirimiphos methyl, Efficacy, Malaria, Benin

\section{Background}

Malaria is a major public health problem and Anopheles gambiae is one of the major vectors of this disease in sub-Saharan Africa [1]. The current effective vector control tools include the use of Long Lasting Insecticide Nets (LLIN) and Indoor Residual Spraying (IRS) [2]. In

\footnotetext{
* Correspondence: rockypremier@yahoo.fr

${ }^{1}$ Centre de Recherche Entomologique de Cotonou (CREC), 06 BP 2604 Cotonou, Bénin

${ }^{2}$ Faculté des Sciences et Techniques, Université d'Abomey Calavi, Abomey Calavi, Bénin

Full list of author information is available at the end of the article
}

sub-Saharan Africa and southern Asia, these two methods have shown good results [3,4] but they have their drawbacks.

The main problem with ITNs and IRS is the development of insecticide resistance, particularly pyrethroid-resistance, which has been demonstrated in several populations of Anopheles gambiae [5-8]. In the past decade, the emergence of resistance in populations of An. gambiae to common classes of insecticides used in public health has been reported in many countries in Africa, including Côte d'Ivoire [5], Kenya [9], Benin [10,11], Niger [12], Burkina

\section{Biomed Central}

(c) 2014 Aïkpon et al.; licensee BioMed Central Ltd. This is an Open Access article distributed under the terms of the Creative Commons Attribution License (http://creativecommons.org/licenses/by/4.0), which permits unrestricted use, distribution, and reproduction in any medium, provided the original work is properly credited. The Creative Commons Public Domain Dedication waiver (http://creativecommons.org/publicdomain/zero/1.0/) applies to the data made available in this article, unless otherwise stated. 
Faso [13], Mali [14], Nigeria [15], South Africa [16] and Cameroon [17]. In recent reports [18] widespread distribution of pyrethroid resistance in An. gambiae was shown in southern Benin, and there was a significant increased level of the $k d r$ mutation, which remains the major resistance mechanism detected. The lowest frequency of Ace-1 ${ }^{R}$ was recorded during the same study and may be a sign of encouragement to use carbamates or organophosphates as alternative insecticides to pyrethroids for IRS in Benin. However, Ailkpon and others [19] have recently demonstrated a decrease of An. gambiae susceptibility to bendiocarb after the IRS implementation using bendiocarb in Atacora region in Benin.

In another study [20], which included six months evaluation of various insecticides in experimental huts, three insecticides (Sumithion 40 WP [Fenitrothion]; Actellic EC [Pirimiphos methyl]; and Ficam M [bendiocarb, 800 g/kg]) were effective against Anopheles. However, bendiocarb and pirimiphos methyl are the two products that the National Malaria Control Program (NMCP) has selected for the IRS campaign in 2013 in Atacora region in Benin. This study was conducted at the experimental hut level and it is difficult to extrapolate from these results what might happen at a larger-scale community level [20,21].

The present study aims to evaluate the persistence of the biological efficacy of Actelic 50 EC IRS and it entomologic impact on malaria transmission after large-scale implementation in areas of high resistance to pyrethroids in An. gambiae.

\section{Methods}

\section{Study area}

The study was carried out in Atacora-Donga region located in the North-west of Benin and includes three districts: Kouandé, Tanguiéta and Copargo (Figure 1). The three districts covered 7,543 $\mathrm{km} 2$ and had an estimated population of 287,935 in 2012. Atacora-Donga region has a sub-equatorial type climate with one dry season (December-May) and only one rainy season (June to November). The annual mean rainfall is $1,300 \mathrm{~mm}$ and the mean monthly temperature ranges between 22 and $33^{\circ} \mathrm{C}$. The region is irrigated by three major rivers: the Mekrou, the Pendjari and the Alibori. The major economic activity is agriculture and it is characterized by the production of cotton and millet where various classes of pesticides are used for pest control.

\section{Indoor residual spraying (IRS) campaigns 2013}

Pirimiphos methyl was selected for spraying on the walls for 2013 IRS campaign in Kouandé, Tanguiéta districts. Studies have shown that this insecticide was efficient in phase II evaluations against malaria vectors [20]. ACTELLIC 50 EC (Syngenta) was therefore applied. The recommended dilution rate for residual application for the control of mosquitoes is 1-2 g of active ingredient per square meter of spray surface. Thus, $50-100 \mathrm{ml}$ of ACTELLIC $50 \mathrm{EC}$ is needed in 1 liter of spray. The 15-liter-capacity H. D. Hudson Manufacturing Company (Chicago, IL) $67422 \mathrm{AD}$, Hudson X-pert spray pumps, recommended by the WHO for use in IRS, was used. One liter $(1000 \mathrm{ml})$ of ACTELLIC 50EC was mixed in 10 liters of clean water in the spray can and pressurized to 55 Psi. The application rate was $1 \mathrm{~m}$ in 2.2 or $4.5 \mathrm{~s}$ for $2 \mathrm{~m}$ height of wall [22]. Only one round of IRS was carried out per year in the beginning of the rainy season in June. The IRS operation was performed by volunteers chosen from the local community who were trained by the PMI IRS partner (Abt associate team). According to Abt associate, the coverage rate was more than $90 \%$ of the households in the target districts. Copargo district, which has similar characteristics to the treated districts (climate, agricultural practices, LLIN coverage) was selected as control and was not treated. Twenty $\mathrm{km}$ separate the control (untreated) villages from the treated districts.

\section{Mosquito sampling Human landing catch}

In each district, two villages were selected, and two houses were chosen per village for mosquito collection to monitor malaria transmission. Monthly, mosquito collections were carried out from 6 p.m. to 6 a.m. inside and outside houses using a mouth aspirator, by human volunteers who had previously given consent. Two nights of mosquito collections a month were carried out for three months. A total of six night catches were conducted in each district. These catches were made from June to August 2013 (after IRS intervention) during the recommended duration of effective action of pirimiphos methyl by WHOPES, which is between 2 and 3 months. In each district, two houses and four collectors were selected per area for the collection of mosquitoes. The recorded data were used to assess the aggressiveness (HBR), the physiological age and the entomological inoculation rate vectors (EIR).

\section{Exit window trap catch}

Moreover, in order to assess the impact of interventions on exit induced by the presence of Actellic $50 \mathrm{EC}$, we sampled mosquitoes using window exit traps and morning pyrethrum spray catches (PSC). Therefore, in each area, eight bedrooms were selected for mosquito collection in the morning. Exit traps were put over the windows of every bedroom retained. Mosquitoes were collected for 2 nights each month from 6 p.m. to 6 a.m. next day. The houses where the traps were set were selected based on the number of people who slept in them (01 sleeper per hut). The houses were built of mud and wood with a sheet-metal roof and the eve was tight. The area between the upper walls and the roof is closed. 


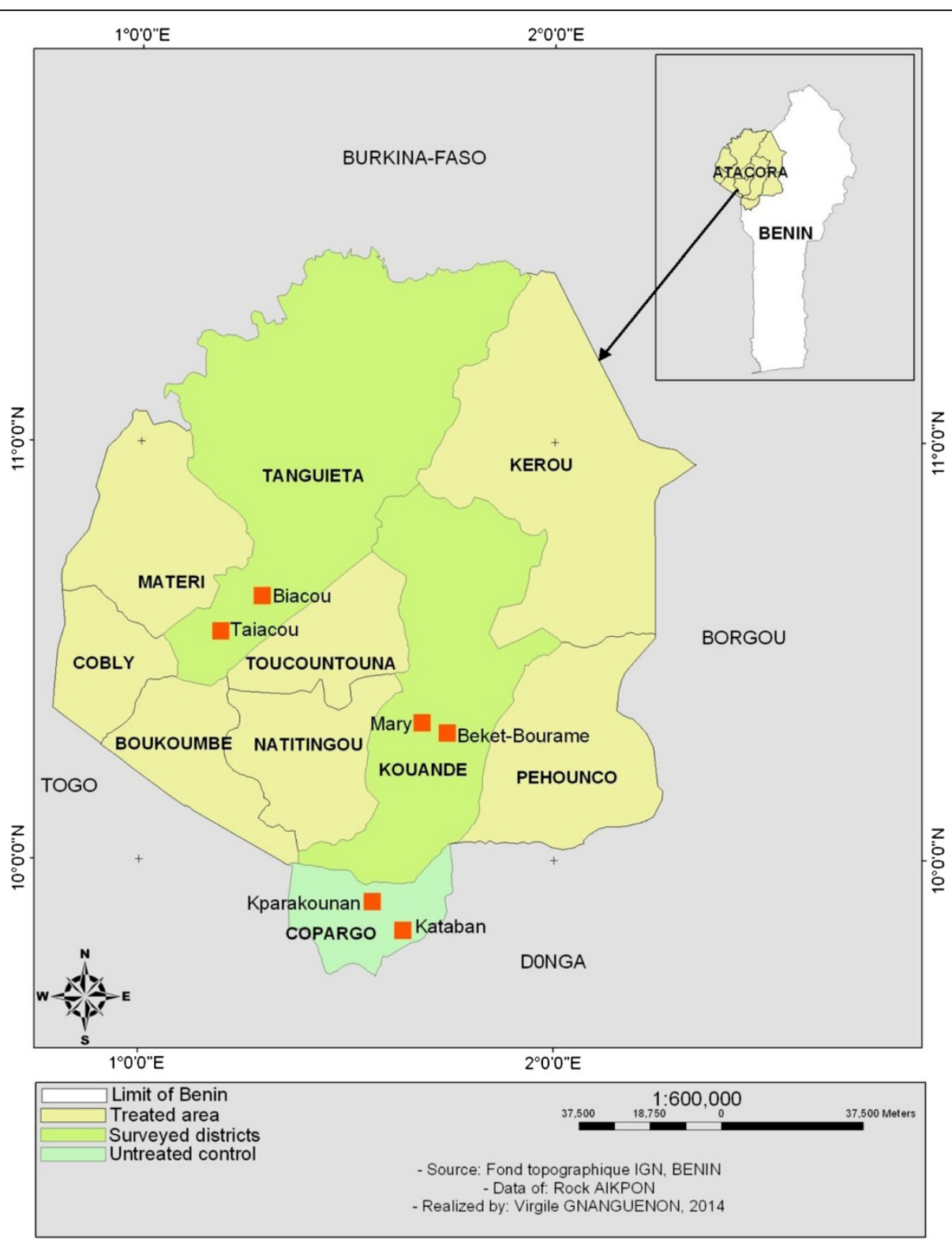

Figure 1 Map of the study area.

The exit window traps used were made of a terylene netting mounted on a $30 \mathrm{~cm}$ cubical metallic frame. The entrance side was drawn into a truncated cone with a $2.5 \mathrm{~cm}$ diameter hole at its apex, which was $2.5 \mathrm{~cm}$ from the opposite face of the trap. In addition to that, mosquitoes resting in the house were collected by Morning Spray Catch (MSC) from 7 a.m. to 9 a.m. The collections from the window traps were done in the morning using a mouth aspirator. Morning pyrethrum spray catches were done using pyrethrum spray and white canvas spread on the floor to collect knocked down mosquitoes. These two sampling methods led to an accurate estimation of the total density of mosquito species in the treated houses and the proportion of female mosquitoes exiting from the houses. Exit rate is estimated by mosquitoes that have escaped treated walls and have been retained in the exit window traps. Anopheles mosquitoes collected were classified according to the state of their abdomens.

\section{Bioassay Test}

The residual activity of ACTELLIC $50 \mathrm{EC}$ on the sprayed surface was monitored for a period of 4 months using WHO cone tests [23].

\section{Biological materials}

The susceptible strain "Kisumu" of An. gambiae originate from Kenya and were bred and maintained in the insectary 
of the Entomological Research Centre of Cotonou (CREC) and were used for the bioassays. A local population of $A n$. gambiae from Atacora, collected as larvae and raised to adulthood in the insectary were also used.

\section{Cone bioassay procedure}

Bioassays were carried out monthly on walls of twelve houses randomly selected in the study area. Untreated surfaces were used as control. The efficacy and the residual life of the Actellic 50 EC on the treated wall (mud and cement) was evaluated using WHO cone tests [23]. This test consists of introducing ten to fifteen unfed two to five-day-old female mosquitoes into a plexiglas cone attached to the insecticide-treated wall for 30 minutes. After exposure, the mosquitoes were placed in small cups, provided with sugar solution and maintained at $27 \pm 2^{\circ} \mathrm{C}$ with a relative humidity of $80 \pm 10 \%$ for 24 hours to assess delayed mortality. Tests were considered as invalid and repeated when control mortalities exceeded $20 \%$. When control mortalities were less than $20 \%$, but exceeded $5 \%$, a correction of mortality was made using Abbot's formula [24].

\section{Laboratory processing}

After each night catch, Anophelines were morphologically identified to species using taxonomic keys of Gillies \& De Meillon [25] and Gillies \& Coetzie [26]. Ovaries from randomly selected female An.gambiae s.l. specimens captured on human landing catches were dissected to determine parity rate, by observing the degree of coiling of ovarian tracheoles [27]. Mosquito infectivity rates were determined from head and thorax of all female anopheline specimens by enzyme-linked immunosorbent assay (ELISA) using monoclonal antibodies against Plasmodium falciparum circumsporozoite protein (CSP) as described by Wirtz et al. [28]. The carcass of these females (abdomens, wing and legs) were stored in individual tubes with silicagel and preserved at $-20^{\circ} \mathrm{C}$ in the laboratory for identification of species and characterization of molecular forms within the An.gambiae complex as previously described [29,30].

\section{Data analysis}

The human biting rate [number of bites/man/night] (ma), the sporozoite rate (Is) and the entomological inoculation rate (EIR) were determined. The percentages of reduction of biting rate (HBR) and EIR in the treated districts compared to the control were evaluated. Parturity rates, exophily and blood feeding rate were calculated. Comparisons of these rates were made by the Chi-square test.

\section{Ethical consideration}

Ethical approval for this study was granted by the Ethical Committee of the Ministry of Health in Benin. The mosquito collectors gave prior informed consent and they were vaccinated against yellow fever. They were also subjected to regular medical check-ups with preventive treatments of malaria.

\section{Results}

Bioassay tests

The results of bioassay tests on cement and mud surfaces are shown in Figure 2. A total of 1440 wild strain female An. gambaie s.l and 1512 An. gambiae s.s. susceptible strain Kisumu were exposed on the treated surface during the 4 month period. The bioassay test was conducted monthly from May to August 2013. From $\mathrm{T}_{0}$ (24 hours after spray operation), the percentage mortalities after $24 \mathrm{~h}$ of observation were $100 \%$. However, after one month, the percentage mortality for wild strain $A n$. gambiae was $99 \%$ on cement and $94 \%$ on mud before a gradual decline (Figure 2). The residual effect of Actellic 50 EC (>80\% mortality in cone bioassays) lasted three months. Comparing the persistence of Actellic 50 EC on the cement and mud wall surfaces showed a significant difference $(\mathrm{P}<0.05)$. At 3 months, the mortality of

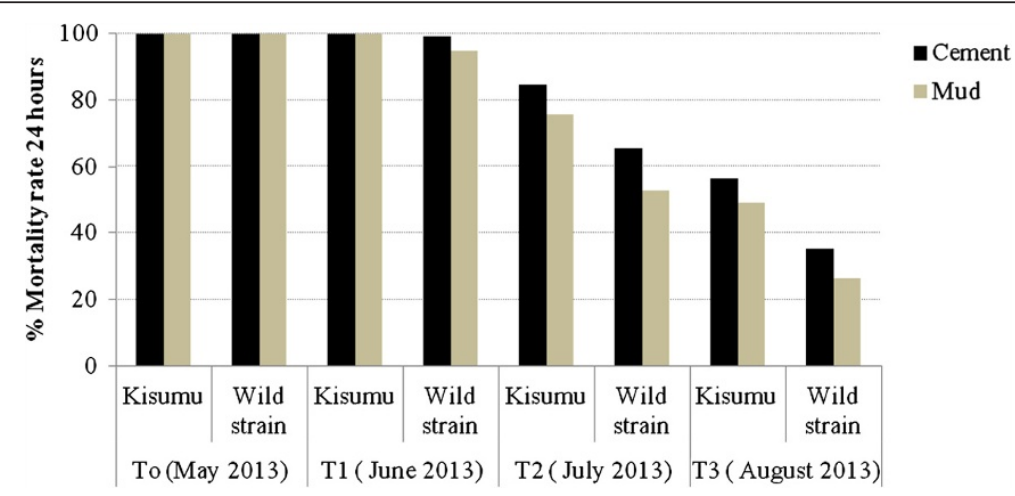

Figure 2 Three months residual efficacy of Actellic 50 EC indoor residual spraying in Atacora. $\left(T_{0}=24\right.$ hours after treatement; $T_{1}=30$ days after treatement; $T_{2}=60$ days after treatement; $T_{3}=90$ days after treatement). 
Kisumu has decreased to $56.5 \%$ on cement wall surfaces against $49 \%$ on mud wall surfaces.

\section{Anopheles gambiae s. I species identification}

A total of $341 A n$. gambiae s.l mosquitoes were analyzed for species identification. An. gambiae s.s. and An. coluzzii are sympatric in the study area. However, $A n$. gambiae was predominant $(74.78 \% ; n=255)$ (Figure 3 ).

\section{Impact of IRS on HBR of An. gambiae}

The results of our research show a lower human biting rate (HBR) in the treated area. During the study period, the An. gambiae HBR was $0.55 \mathrm{bite} /$ person/night in intervention areas against 9.56 bites/person/night in the control. The reduction of human biting rate was $94.25 \%$ (Table 1).

\section{Impact of IRS on EIR of An. gambiae}

The EIR in the control area was 2.11 infected bites/person/night against 0.016 infected bites/person/night in the treated districts (Table 1). In the control area, the rate was very high (63.3 infected bites/man/month). The comparison of EIR observed in treated areas and the control revealed a dramatic reduction of $99.24 \%$ in treated districts.

\section{Impact of IRS on longevity of An. gambiae}

A total of 131 ovaries of An. gambiae were dissected. The parity rate of $A n$. gambiae was $20 \%$ in the treated districts against $49.41 \%$ in the control (Figure 4 ). We observed a significant reduction of longevity $(\mathrm{p}<0.001)$. The IRS area was not conducive for mosquito survival.

Impact of IRS on An. gambiae blood feeding rate in treated districts and the control

The blood feeding rate observed in the treated areas was $89.47 \%(17 / 19)$ against $96.76 \%(118 / 122)$ in the control (Figure 5). The difference was not significant. Despite IRS

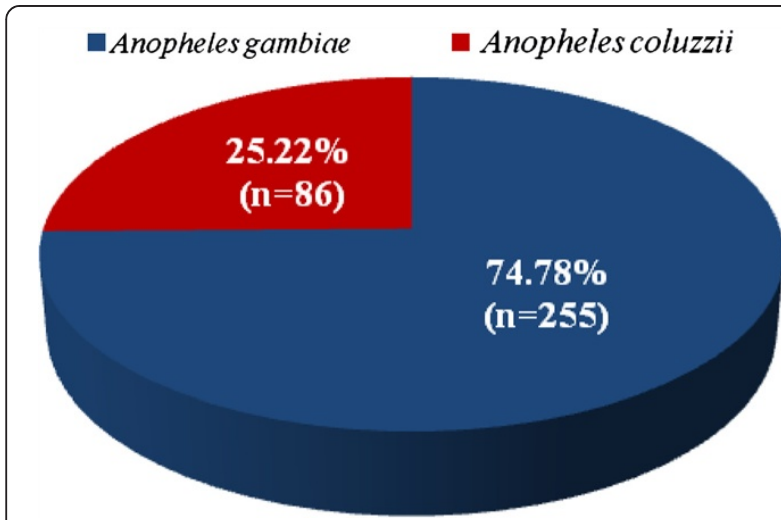

Figure 3 An. gambiae complex composition in the study area.
Table 1 Entomological Inoculation Rate (EIR) and Human Biting Rate (HBR) observed in intervention area and the control

\begin{tabular}{lccc}
\hline Variables & $\begin{array}{c}\text { Treated districts } \\
\text { (Tanguiéta, Kouandé) }\end{array}$ & $\begin{array}{c}\text { Control } \\
\text { (Copargo) }\end{array}$ & \% reduction \\
\hline Total & 35 & 306 & - \\
Person night & 64 & 32 & - \\
HBR & 0,55 & 9,56 & 94,25 \\
S\% & 0,03 & 0,22 & - \\
EIR (b/m/n) & 0,016 & 2,11 & 99,24 \\
EIR/month & 0,48 & 63,3 & - \\
\hline
\end{tabular}

$\mathrm{S} \%=$ Sporozoite index

$\mathrm{HBR}=$ Human Bite Rate.

$\operatorname{EIR}(\mathrm{b} / \mathrm{m} / \mathrm{n})=$ Entomological Inoculating Rate (infected bite/man/night).

implementation, a non-negligible proportion of mosquitoes fed on humans.

Impact of IRS in induced exophily in An. gambiae in localities under IRS and the control

The exit rate of $A n$. gambiae in the control was $14 \%$. Compared to the control, there is a significant increase of exit rate of An. gambiae in the treated districts. In those districts, the exit rate was $100 \%$. This shows that the mosquitoes that enter houses do not manage to stay there and are obliged to exit houses.

\section{Discussion}

The strategy of indoor residual spraying (IRS) with pirimiphos methyl implemented by the National Malaria

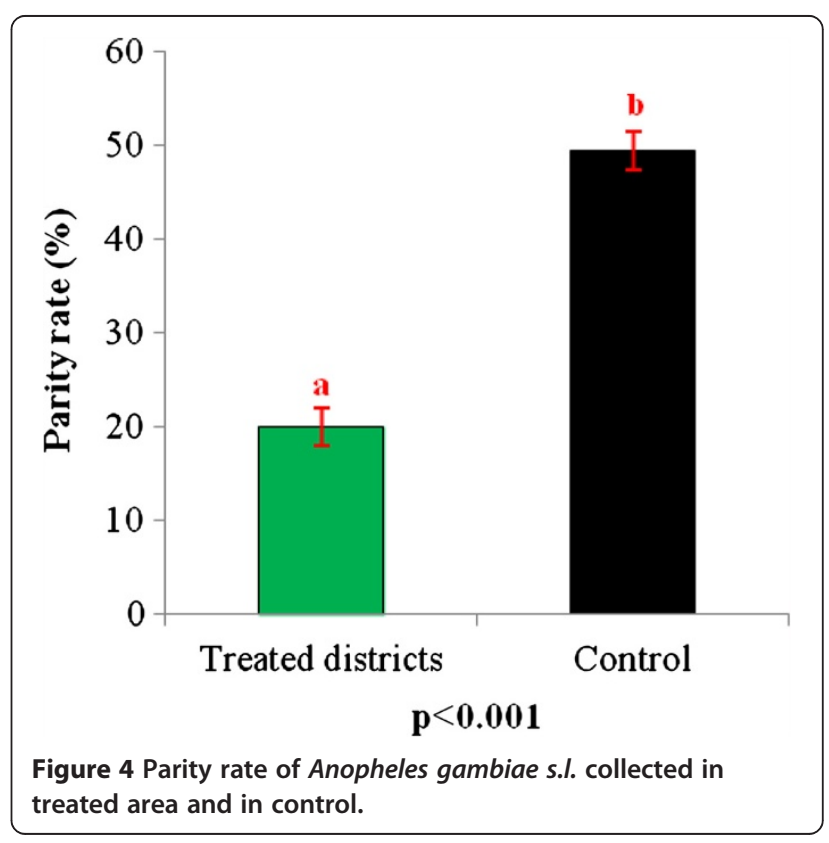




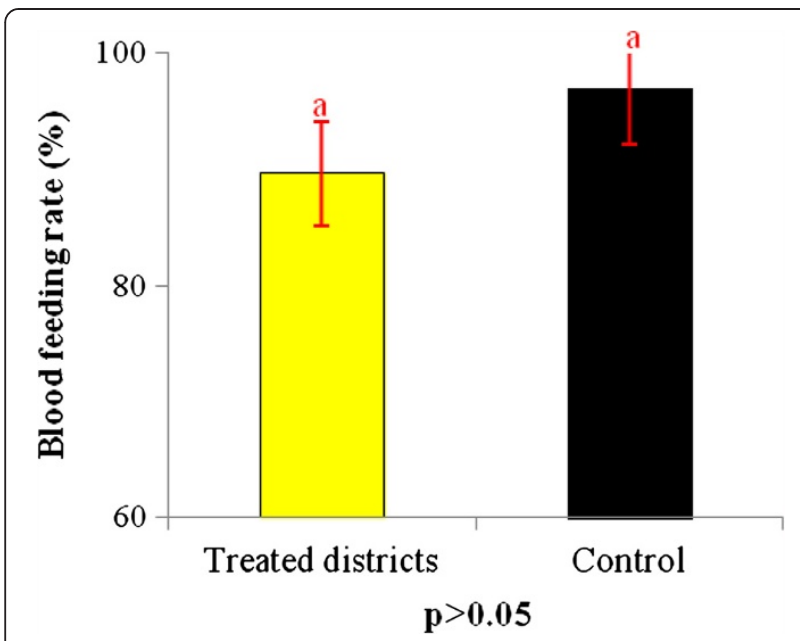

Figure 5 Percentage of blood feeding An. gambiae collected in IRS by Pyrethrum Spray Catch (PSC) and in exit windows traps in intervention area and the control.

Control Program (NMCP) in the Atacora region had a great impact on malaria transmission. In the districts under intervention, the density of An. gambiae (human biting rate) and the entomological inoculation rate (EIR) were significantly reduced.

In this study, two members of An. gambiae complex were found in sympatry (An. gambiae and An. coluzzii) and their distribution agree with previous findings in Benin that reported both $\mathrm{M}$ and $\mathrm{S}$ forms with the predominance of S forms in savannah areas [31].

The results have shown that the biting rate of Anopheles dropped drastically in treated districts compared to the control. This drastic drop is due to the lethal effect of pirimiphos methyl on the anophelines resistant to pyrethroids [20].

Indeed, comparing the number of An. gambiae bites that a person receives in one night in the treated districts and in the control, the rates were significantly reduced. These results were consistent with those of Akogbéto et al. [32] and Ossè et al. [33] with bendiocarb IRS in the south of Benin.

The unpleasant atmosphere created by the presence of pirimiphos methyl on the walls inside houses is harmful to the mosquitoes. This atmosphere results in an increase in the exit rate in the treated districts (Figure 6). Thus, some Anopheles mosquitoes that managed to enter houses failed to obtain blood meals before exiting. However, some succeeded in obtaining blood meals inside houses (Figure 5). The proportion of fed An. gambiae collectedin window exit traps in treated districts was not significantly different from that observed in the untreated area (control). When mosquitoes enter the houses, even those houses that are treated, they go directly to their host to obtain a blood

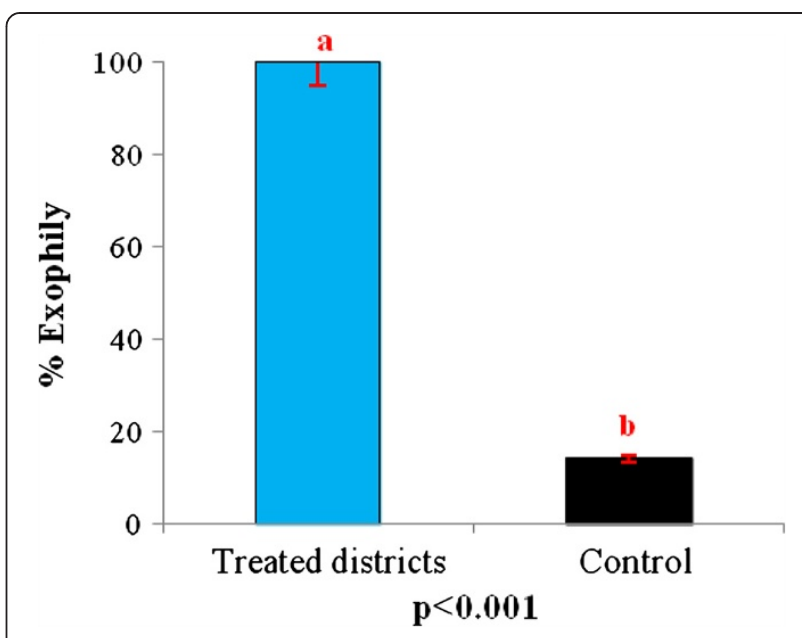

Figure 6 Exit rate for Anopheles gambiae from pirimiphos methyl treated walls.

meal before resting on walls or seeking to escape if the houses are treated. This situation was found in experimental huts for many insecticides $[20,21]$. This finding explains why we have proposed that the NMCP always invite communities who are protected by IRS to add sleeping under mosquito nets to supplement malaria control efforts.

The EIR was low in treated districts. This shows that the IRS performed in those districts were a great success. Indeed, we had a reduction of $99.24 \%$ of EIR. Despite the effectiveness of IRS, this method has its limitations. A major concern is the low residual activity of actellic $50 \mathrm{EC}$, which is a maximum of three months. This confirms the the effective minimum duration action of $2-3$ months recommended by WHOPES. The period of transmission of malaria is six months in Atacora (from June to November). The low persistence of Actellic 50 EC cannot cover all the periods of transmission. For that reason, we have to suggest to the NMCP, the use of the CS formulation (Actellic CS) for the future IRS campaigns in Atacora. Indeed this formulation recently received the ratification of the WHOPES and can be used in Benin.

\section{Conclusion}

The use of pirimiphos methyl in IRS in Atacora department with the PMI support had a significant impact on malaria transmission in the treated areas. The results show that in intervention areas, the human biting rate of mosquitoes dropped spectacularly. A reduction of $99.24 \%$ in the entomological inoculation rate was recorded, due to the decline in the lifespan of An. gambiae and high exophily induced by pirimiphos methyl on mosquitoes. However, the limitation that consists of the low residual activity of Actellic 50 EC remains to be resolved, which can be achieved by a change of the formulation. 


\section{Competing interests}

The authors declare that they have no competing interests.

\section{Authors' contributions}

RA, MS, FT, MO, OO, FOA, RM and MA designed the study. RA, FT, OO, MO and MA carried out the field activities. RA drafted the manuscript and analyzed the data. MA and FOA critically revised the manuscript. MA conceived and designed the study and revised the manuscript for intellectual content. All authors read and approved the final manuscript.

\section{Acknowledgment}

This work was financially supported by PMI (President's Malaria Initiative) through USAID. We thank the Ministry of Higher Education and Scientific Research (MESRS) and the team of CREC for their technical assistance during field work and the laboratory. We also thank the people of Atacora for their collaboration.

\section{Author details}

${ }^{1}$ Centre de Recherche Entomologique de Cotonou (CREC), 06 BP 2604 Cotonou, Bénin. ${ }^{2}$ Faculté des Sciences et Techniques, Université d'Abomey Calavi, Abomey Calavi, Bénin. ${ }^{3}$ National Malaria Control Programm (NMCP), Ministry of Health, Cotonou, Benin. ${ }^{4}$ Center of Desease Control, Atlanta, USA.

\section{Received: 5 May 2014 Accepted: 25 May 2014}

\section{Published: 30 May 2014}

\section{References}

1. Gillies MT, Coetzee M: A supplement to the Anophelinae Africa South of the Sahara (Afrotropical region), Johannesburg, South Africa. S Afr Inst Med Res 1987, 55:1-143.

2. Beier JC, Keating J, Githure JI, Macdonald MB, Impoinvil DE, Novak RJ: Integrated vector management for malaria control. Malar J 2008, 7(1):54.

3. Curtis CF, Abraham E, Mnzava P: A comparison of use of a pyrethroid either for house spraying or for bednet treatment against malaria vectors. Trop Med Int Health 1998, 3:619-631.

4. Rowland M: Malaria control: bednets or spraying? Malaria control in the Afghan refugee camps of western Pakistan. Trans $R$ Soc Trop Med Hyg 1999, 93:458-459.

5. Elissa N, Mouchet J, Rivière F, Meunier JY, Yao K: Resistance of Anopheles gambiae s.s. to pyrethroids in Côte d'Ivoire. Ann Soc Belg Med Trop 1993, 73:291-294.

6. Akogbéto M, Yakoubou S: Résistance des vecteurs du paludisme vis-à-vis des pyréthrinoïdes utilisés pour l'imprégnation des moustiquaires au Bénin, Afrique de I'Ouest. Bull Soc Pathol Exot 1999, 92:123-130.

7. Chandre F, Darriet F, Duchon S, Finot L, Manguin S, Carnevale P, Guillet P: Modifications of pyrethroid effects associated win $\mathrm{kdr}$ mutation in Anopheles gambiae. Med Vet Entomol 2000, 14:81-88.

8. Akogbeto M, Djouaka RF, Kinde-Gazard DA: Screening of pesticide residues in soil water samples from agricultural settings. Malar $J$ 2006, 5:22.

9. Vulule JM, Beach RF, Atieli FK, McAllister JC, Brogdon WG, Roberts JM, Mwangi RW, Hawley WA: Elevated oxidase and esterase levels associated with permethrin tolerance in Anopheles gambiae from Kenyan villages using permethrin impregnated nets. Med Vet Entomol 1999, 13:239-244

10. Corbel V, N'Guessan R, Brengues C, Chandre F, Djogbenou L, Martin T, Akogbeto M, Hougard JM, Rowland M: Multipleinsecticide resistance mechanisms in Anopheles gambiae and Culex quinquefasciatus from Benin, West Africa. Acta Trop 2007, 101:207-216.

11. Yadouleton AW, Asidi A, Djouaka RF, Braïma J, Agossou CD, Akogbeto MC: Development of vegetable farming: a cause of the emergence of insecticide resistance in populations of Anopheles gambiae in urban areas of Benin. Malar J 2009, 8:103.

12. Czeher C, Labbo R, Arzika I, Duchemin JB: Evidence of increasing Leu-Phe knockdown resistance mutation in Anopheles gambiae from Niger following a nationwide longlasting insecticide-treated nets implementation. Malar J 2008, 7:189.

13. Diabate A, Baldet T, Chandre F, Guiguemde RT, Brengues C, Guillet P, Hemingway J, Hougard JM: First report of the kdr mutation in
Anopheles gambiae M form from Burkina Faso, West Africa. Parassitologia 2002, 44:157-158.

14. Fanello C, Petrarca V, Della Torre A, Santolamazza F, Dolo G, Coulibaly M, Alloueche A, Curtis CG, Toure YT, Coluzzi M: The pyrethroid knock-down resistance gene in the Anopheles gambiae complex in Mali and further indication of incipient speciation within An. gambiae s.s. Insect Mol Biol 2003, 12:241-245.

15. Awolola TS, Brooke BD, Koekemoer LL, Coetzee M: Resistance of the malaria vector Anopheles gambiae s.s. to pyrethroid insecticides, in south-western Nigeria. Ann Trop Med Parasitol 2002, 96:849-852.

16. Hargreaves K, Koerkemoer LL, Brooke B, Hunt RH, Mthembu J, Coetzee M: Anopheles funestus resistant to pyrethroid insecticides in South Africa. Med Vet Entomol 2000, 14:181-189.

17. Etang J, Manga L, Chandre F, Guillet P, Fondjo E, Mimpfoundi R, Toto JC, Fontenille D: Insecticide susceptibility status of Anopheles gambiae s.l. (Diptera: Culicidae) in the Republic of Cameroon. J Med Entomol 2003, 40:491-497

18. Aïkpon R, Agossa F, Ossè R, Oussou O, Aïzoun N, Oké-Agbo F, Akogbéto M: Bendiocarb resistance in Anopheles gambiae s.l. populations from Atacora department in Benin, West Africa: a threat for malaria vector control. Parasit Vectors 2013, 6:192.

19. Djogbénou L, Pasteur N, Bio-Bangana S, Baldet T, Irish SR, Akogbeto M, Weill M, Chandre F: Malaria vectors in the Republic of Benin: distribution of species and molecular forms of the Anopheles gambiae complex. Acta Trop 2010, 114:116-122.

20. Agossaa F, Aikkpon R, Azondekon R, Govoetchan R, Padonnou GG, Oussou O, Oke-Agboa F, Akogbeto M: Efficacy of various insecticides recommended for indoor residual spraying: pirimiphos methyl, potential alternative to bendiocarb for pyrethroid resistance management in Benin, West Africa. Trans R Soc Trop Med Hyg 2014, 108:84-91.

21. Akogbéto MC, Padonou GG, Gbénou D, Irish S, Yadouleton A: Bendiocarb, a potential alternative against pyrethroid resistant Anopheles gambiae in Benin. West Africa. Malar J 2010, 9:204

22. [WHO] World Health Organization: Manual for Indoor Residual Spraying: Application for Residual Sprays for Vector Control, WHO/CDS/NTD/ WHOPES/GCDPP/2007.3. 3rd edition. Geneva, Switzerland: WHO; 2007.

23. [WHO] World Health Organization: Guidelines for Testing Mosquito Adulticides for Indoor Residual Spraying and Treatment of Mosquito Nets. Geneva, Switzerland: WHO; 2006.

24. Abbott $\mathrm{W}$ : A method of computing the effectiveness of an insecticide. J Econo Entomol 1975, 18:265-267.

25. Gillies MT, De Meillon D: The Anophelinae of Africa South of the Sahara. Publ South Afri Inst Med Res 1968, 54:343.

26. Gillies MT, Coetzee MA: Supplement to the Anophelinae of Africa South of the Sahara, 2nd edn. Publ South Afri Inst Med Res 1987, 55:143.

27. Detinova TS, Gillies MT: Observations on the Determination of the Age Composition and Epidemiological Importance of Populations of Anopheles gambiae Giles and Anopheles funestus Giles in Tanganyika. Bull World Health Organ 1964, 30:23-28.

28. Wirtz RA, Ballou WR, Schneider I, Chedid L, Gross MJ, Young JF, Hollingdale M, Diggs CL, Hockmeyer WT: Plasmodium falciparum: immunogenicity of circumsporozoite protein constructs produced in Escherichia coli. Exp Parasitol 1987, 63:166-172.

29. Scott JA, Brogdon WG, Collins FH: Identification of single specimens of the Anopheles gambiae complex by the polymerase chain reaction. Am J Trop Med Hyg 1993, 49:520-529.

30. Favia G, Lanfrancotti A, Spanos L, Siden Kiamos I, Louis C: Molecular characterization of ribosomal DNA polymorphisms discriminating among chromosomal forms of Anopheles gambiae s.s. Insect Mol Biol 2001, 10:19-23.

31. Aïkpon R, Aïzoun N, Sovi A, Ossè R, Oussou O, Govoetchan R, Oké-Agbo F, Akogbéto M: Increase of Ace-1 resistance allele in the field population of Anopheles gambiae following a large scale indoor residual spraying (IRS) implementation using bendiocarb in Atacora region in Benin, West Africa. J cell Anim Biol 2014, 8(1):15-22.

32. Akogbéto M, Padonou G, Bankolé H, Kindé Gazard D, Gbédjissi G: Dramatic decline of malaria transmission after implementation of large-scale Indoor Residual Spraying using bendiocarb in Bénin, West Africa, an area of high 
Anopheles gambiae resistance to pyrethroids. Am J Trop Med Hyg 2011, 85(4):586-593.

33. Ossè R, Aikpon R, Padonou G, Oussou O, Yadouléton A, Akogbéto M: Evaluation of the efficacy of bendiocarb in indoor residual spraying against pyrethroid resistant malaria vectors in Benin: results of the third campaign. Parasit Vectors 2012, 5:163.

doi:10.1186/1756-3305-7-256

Cite this article as: Aikpon et al:: Good performances but short lasting efficacy of Actellic 50 EC Indoor Residual Spraying (IRS) on malaria transmission in Benin, West Africa. Parasites \& Vectors 2014 7:256.

\section{Submit your next manuscript to BioMed Central and take full advantage of:}

- Convenient online submission

- Thorough peer review

- No space constraints or color figure charges

- Immediate publication on acceptance

- Inclusion in PubMed, CAS, Scopus and Google Scholar

- Research which is freely available for redistribution 